\title{
Um modelo de otimização linear para o planejamento agregado da produção e logística de sementes de milho
}

\author{
Rogério de Ávila Ribeiro Jungueira \\ Logtrac Consultores Associados S/C. \\ Reinaldo Morabito \\ Universidade Federal de São Carlos
}

\begin{abstract}
Resumo
A produção de sementes de milho envolve uma cadeia de produção agroindustrial complexa cujos agentes devem primar por oferecer produtos de alta qualidade a um baixo custo para se manterem competitivos no mercado. Neste trabalho, um modelo de otimização linear é proposto para auxiliar nas decisões do planejamento tático da produção, estocagem e transporte de sementes de milho, de forma a minimizar custos de produção, logísticos e fiscais, atendendo às restrições de programação da colheita, capacidade das plantas e demanda dos clientes. Para verificar a coerência do modelo e validar a abordagem, o modelo foi implementado na linguagem de modelagem GAMS e aplicado para resolver diferentes cenários de um exemplo baseado em dados realistas de uma empresa. Os resultados mostraram a importância de se considerar os custos fiscais de ICMS no planejamento agregado da produção e logística de sementes de milho.
\end{abstract}

\section{A linear optimization model to the aggregate production and logistics planning of corn seeds}

\begin{abstract}
The production of corn seeds involves a complex agro-industrial production chain whose main agents must offer products of high quality and low price to stay competitive in the market. This work proposes a linear optimization model to support decisions in the tactical planning of production, storing and transportation of corn seeds, designed to minimize production, logistics and tax costs and to satisfy crop planning, plant capacity and client demand constraints. In order to verify the consistency of the model and validate the approach, the model was implemented in the GAMS modeling language and applied to solve different scenarios of an example based on realistic data of a company. The results showed the importance of considering tax costs in the production and logistics aggregate planning of corn seeds.
\end{abstract}

Key words

Corn seeds, production and logistics planning, linear optimization, tributary planning, ICMS. 


\section{INTRODUĈ̣̃O}

A produção de sementes de milho envolve uma cadeia de produção agroindustrial complexa, formada pelos macrosegmentos: produção agrícola, industrialização e comercialização. A coordenação eficaz das atividades desta cadeia garante a competitividade da empresa no setor e tem por objetivo prover sementes ao cliente no momento certo, com níveis de qualidade aceitáveis e mínimo custo. Para tanto, instrumentos eficientes para a coordenação desta cadeia são fundamentais, como o planejamento da produção e logística, objeto deste trabalho. Este planejamento agregado possui alto grau de complexidade devido às suas especificidades e à dispersão geográfica da produção agrícola, industrial e da demanda, com as quais é formada uma rede logística. Nesta rede existem múltiplos produtos, definidos no momento da produção agrícola e ajustados às especificidades da região geográfica e do tipo do produtor. Também influenciam a sazonalidade e a variabilidade da produção agrícola e da demanda, dependentes de fatores climáticos e biológicos.

O planejamento determina as quantidades de cada produto a serem transportadas das unidades de produção agrícola para as UBSs (Unidades de Beneficiamento de Sementes), partindo de uma programação de colheita. Estabelece também as quantidades a serem processadas em cada diferente etapa da UBS, respeitando limitações de capacidade, bem como níveis de estoque estabelecidos. Ele determina, além disso, se há transferências entre unidades e se atendem à demanda distribuída em diferentes regiões. Para garantir a eficiência econômica do plano, é necessário considerar os custos de transporte, processamento e fiscais, dependendo do caminho que o produto percorre pela rede.

Dentre os impostos que afetam a cadeia de produção de sementes de milho, o Imposto sobre Circulação de Mercadorias e Serviços (ICMS) tem um papel destacado, pois possui alíquotas diferenciadas ou mesmo isenção, dependendo do roteiro do produto e, assim, o plano de transporte influencia o plano tributário. Portanto, o planejador da produção e logística precisa ter uma visão global da cadeia para ter condições de elaborar um plano efetivo, visualizando todos os custos e restrições de capacidade envolvidos, para diferenciar da regra comumente utilizada no setor, de enviar o milho para a UBS mais próxima da região agrícola.

O objetivo deste trabalho é propor um modelo de otimização linear para apoiar decisões de médio-longo prazo no planejamento tático da produção e logística de sementes de milho. O modelo busca minimizar o custo total de produção e logística, incluindo os custos de transporte entre regiões agrícolas, unidades industriais e de entrega, os custos de processamento e os custos fiscais. Redes produtoras de se- mentes de milho, em geral, possuem múltiplos e dispersos campos de produção agrícola, unidades industriais e pontos de demanda. Associadas às unidades industriais, são relevantes as restrições de capacidade de produção. Além disso, a programação de colheita e a previsão de demanda dos produtos devem ser atendidas.

Diversos trabalhos aplicando modelos de programação matemática para apoiar decisões de planejamento em cadeias agroindustriais são encontrados na literatura. No Brasil, alguns exemplos envolvendo estudos de caso de produção e logística de carne de frango, açúcar e álcool, flores, suco concentrado de laranja, são: TAUBE (1996), Yoshizaki et al. (1996), Colin et al. (1999), Munhoz \& Morabito (2001a, 2001b), Caixeta-Filho et al. (2002), Kawamura et al. (2005) e Paiva \& Morabito (2006). Não foram encontrados trabalhos estudando o planejamento de produção e logística na cadeia agroindustrial de sementes de milho. Outro estudo relacionado ao presente trabalho é o de Yoshizaki (2002), que verificou a influência dos custos tarifários com relação à localização de centros de distribuição, enfocando a distribuição de bens de consumo no nível de decisão estratégico. No presente trabalho, propõe-se conhecer a influência do ICMS na cadeia de produção de sementes de milho, enfatizando decisões de nível tático.

planejamento determina as quantidades de cada produto a serem transportadas das unidades de produção agrícola para as UBSs.

Mitroff et al. (1974) sugeriram um modelo de resolução de problemas utilizando uma visão sistêmica (Figura 1), representado por seis processos básicos: conceituação (interpretação da realidade ou partes dela em um modelo conceitual), modelagem (representação do modelo conceitual por um modelo científico), resolução do modelo (processo de obtenção de uma solução para o modelo científico), feedback (análise da coerência entre a solução obtida e o modelo conceitual), implementação (processo de aplicação da solução obtida na realidade ou situação problema) e validação (verificação de se o modelo científico corresponde à realidade ou ao recorte da realidade considerado). Outros autores também sugeriram modelos de resolução de problemas similares ao da Figura 1 (ARENALES et al., 2006).

Neste trabalho, o processo de conceituação consiste na definição dos objetivos, do escopo, das variáveis de controle e das relações causais conhecidas do plano de produção e logística de uma empresa produtora de sementes de milho. 
Foram utilizados conhecimentos já consolidados na literatura e a vivência de um dos autores nas atividades de consultoria na Empresa A, além de visitas supervisionadas pelo gerente de produção na Empresa B. Ambas as empresas atuam no setor de sementes e uma grande parcela da carteira de produtos está relacionada com sementes de milho. As duas seções a seguir apresentam as principais características do processo produtivo e da componente fiscal do custo total considerado.

O processo de modelagem consiste na decodificação das principais variáveis de decisão em um modelo de programação matemática, no caso de otimização linear e representando a realidade das Empresas A e B. A modelagem do presente problema é discutida na seção "Modelagem do problema", onde são definidos os parâmetros e as variáveis de decisão, a função objetivo e as restrições do modelo de programação linear, além do processo de resolução do modelo por meio da linguagem de modelagem GAMS (General Algebraic Modeling System) com o solver CPLEX. Na seqüência, as soluções deste modelo linear de redes baseadas nos dados da Empresa A são confrontadas com o comportamento esperado pelo modelo conceitual. Por conveniência e sem perda de generalidade, estas redes foram reduzidas em tamanho para simplificar a análise e proteger interesses da empresa. $\mathrm{O}$ intuito aqui é evidenciar o processo de feedback sugerido por Mitroff et al. (1974). Os resultados mostram a importância de se considerar custos fiscais no modelo de planejamento agregado da produção e logística de sementes de milho, em especial o ICMS, no Brasil. Finalmente, são apresentadas as considerações finais do estudo e as sugestões de pesquisas futuras.

\section{PROCESSO PRODUTIVO}

Esta seção caracteriza resumidamente o processo tecnológico no qual ocorre a produção de sementes de milho, necessário para compreender a modelagem em termos das hipóteses assumidas, da determinação dos índices, da divisão dos estágios e dos momentos em que é possível a estocagem. Para mais detalhes deste sistema de produção, o leitor pode consultar Junqueira (2006). A produção agrícola é a primeira fase de processamento da cadeia de produção agroindustrial de sementes de milho. Nela são definidos os produtos a serem comercializados e o padrão de qualidade do produto final, já que os demais segmentos se concentram em minimizar a perda de qualidade, mas não podem melhorá-la. As decisões do modelo proposto na seção "Modelagem do problema" não envolvem diretamente os processos dessa etapa, mas utilizam o resultado dela, que é a programação de colheita, como condição de contorno para o modelo. Além disso, auxilia na compreensão de dois índices do modelo: o tipo de colheita e o produto, determinados nessa etapa.

Figura 1: Modelo de resolução de problemas.

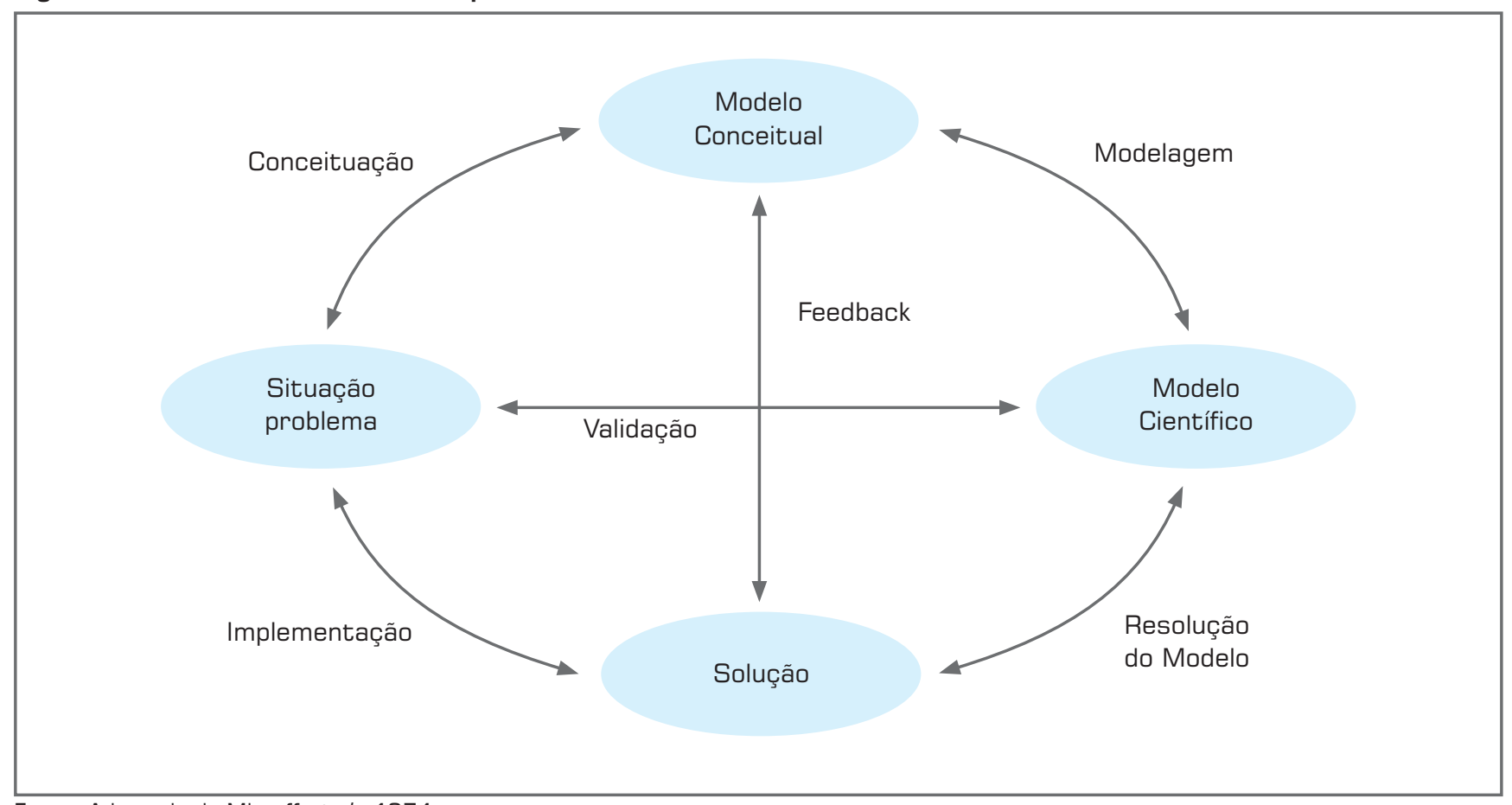

Fonte: Adaptado de Mitroff et al., 1974. 
As sementes de milho podem ser divididas em dois tipos de produtos: variedade e milho híbrido. Para o caso da variedade não há melhoramento genético, ou seja, a semente tem as mesmas características da planta original. Pode ser reproduzida pelo próprio produtor rural, todavia seu desempenho para ele é baixo. Para o milho híbrido há cruzamento entre diferentes espécies, gerando uma semente com características diferentes das matrizes e manipuladas na medida em que são conhecidos os efeitos dos cruzamentos. O híbrido pode ser simples, duplo e triplo.

O híbrido simples é produzido através do cruzamento de duas variedades de milho. A produção deste tipo de híbrido para o produtor agrícola de sementes é bastante instável, em função da sensibilidade deste híbrido aos fatores climáticos e biológicos na produtividade da planta. Portanto, seu custo de produção é alto. Para este tipo de híbrido, com aplicação intensiva de insumos agrícolas, a produtividade esperada para o produtor rural é alta. Com isso, embora possua alto custo de produção, o preço de venda atinge valores altos, podendo gerar altas margens de lucro.

Já o híbrido duplo é produzido pelo cruzamento de uma variedade e um híbrido simples. Ao contrário do híbrido simples, sua produção para o produtor agrícola de sementes é mais estável com relação à produtividade esperada. Por isso, possui baixo custo de produção. Entretanto, sua produtividade para o produtor rural é baixa, embora seja maior que a da variedade. Por outro lado, para atingir o rendimento esperado, não necessita de uma aplicação tão intensiva de insumos. Com isso, embora possua baixo custo de produção, o preço de venda não atinge valores altos e as margens de lucro são bem menos atrativas que as dos híbridos simples.

O híbrido triplo é produzido através do cruzamento de dois híbridos simples, ou um híbrido duplo e uma variedade. Embora seja menos estável que a do híbrido duplo, a produção agrícola de sementes do híbrido triplo é mais estável que a do híbrido simples. Sua produtividade ao produtor rural é maior que a do duplo, mas, ainda assim, menor que a do simples. A necessidade de insumos também é intermediária entre o híbrido duplo e o simples. Dessa maneira, o híbrido triplo tem um papel intermediário quanto ao custo de produção e geração de receita.

As fases finais da etapa agrícola são a colheita e o transporte. A colheita do milho pode ser realizada em grãos ou em espigas. Para a produção de sementes é recomendada a colheita em espigas, já que esta preserva a qualidade da semente em termos de germinação e vigor (OLIVEIRA et al, 1997). Entretanto, há casos em que as sementes são colhidas em grãos, especialmente para os produtos mais robustos que sofrem menos injúrias com a colheita mecânica, como algumas variedades e híbridos duplos. O tipo de colheita do milho condicionará o tipo de transporte e os equipamentos utilizados nas primeiras etapas da fase industrial. $\mathrm{O}$ transporte deve ser feito de maneira rápida devido à alta umidade do produto e conseqüente alta taxa de deterioração, conforme condição de perecibilidade. Assim, a matéria-prima, depois de colhida, não pode ser armazenada antes de um processamento prévio para a retirada de sua umidade.

\section{objetivo é propor um modelo de otimização apoiar decisões de médio-longo planejamento tático da logística.}

A etapa de industrialização pode ser dividida em preparo da matéria-prima e beneficiamento. O preparo da matériaprima transforma grãos úmidos ou espigas úmidas vindos do campo em grãos secos, com um mínimo de impurezas por meio de operações de limpeza, secagem e debulha (apenas para o caso de espigas). Dependendo do tipo de matéria-prima, espigas ou grãos, o preparo envolve diferentes processos produtivos. Já o beneficiamento transforma grãos secos no produto final, ou seja, o grão de milho seco, limpo, classificado por tamanho, tratado quimicamente, ensacado e em condições de germinação. Para isso são realizadas operações de limpeza, classificação por tamanho, tratamento e ensaque. Não necessariamente o milho é proveniente do preparo da matéria-prima na UBS; ele também pode ter vindo transferido de outras UBSs, ou preparado em uma unidade independente subcontratada.

A demanda de sementes é um aspecto crítico a ser considerado na sua produção, em função dos erros de sua previsão e da complexidade de seu gerenciamento. Devido à necessidade de obtenção de escala de produção, a empresa tende a comercializar as sementes em áreas mais dispersas geograficamente para poder ampliar seu mercado. Sendo assim, as diversidades de climas e de ambientes de produção interferem na época em que deve estar disponível ao cliente. Além disso, os diversos perfis de produtores rurais de cada região de demanda necessitam de um mix de produtos diferentes.

\section{INFLUÊNCIAS FISCAIS}

A obrigação tributária é criada apenas quando ocorre efetivamente alguma das hipóteses de incidência previstas em lei. No entanto, não é mandatório praticar atos que acarretem na incidência de impostos, ou que os tornem mais onerosos. O fato gerador é a situação prevista em lei necessária e suficiente para a criação desta obrigação. Já a sonegação ocorre quando o fato gerador aconteceu e alguém tenta escondê-lo 
ou descaracterizá-lo. O planejamento tributário, portanto, visa minimizar o ônus tributário incidente sobre os atos e fatos operacionais, administrativos e financeiros, escolhendo a melhor alternativa dentre as legais existentes.

O modelo de planejamento tratado neste trabalho pode impedir o fato gerador do ICMS (por exemplo: escolhendo rotas de entrega do produto acabado que tenham isenção do imposto), ou pode reduzir o montante devido (escolhendo rotas que tenham alíquotas menores). Os artigos 2 , inciso I, e 12, inciso I, da LC 87/96 (CONFAZ, 2006) determinam o fato gerador do ICMS no momento em que as mercadorias saem do estabelecimento. Os Estados, no entanto, podem acrescentar ou adaptar as regras de incidências também analisadas neste estudo. Para os Estados de São Paulo, Minas Gerais e Goiás, onde estão situadas as UBSs da Empresa A, existe isenção de ICMS para operações internas aos Estados e redução na base de cálculo de $60 \%$ para operações interestaduais, com base no Convênio 100 do ICMS de 4-11-97 (CONFAZ, 2006) editado pelo CONFAZ e nas legislações estaduais (Artigo 41 do Anexo I do ICMS-SP em SÃO PAULO, 2006, decreto 43.943, artigo 1ํ da parte 1 do Anexo I do ICMS-MG em MINAS GERAIS, 2006 e artigo 7ํ do Anexo IX, do ICMS-GO em GOIÁS, 2006).

Além disso, há demandas judiciais em que empresas produtoras de sementes com várias unidades produtivas pedem isenção na transferência entre unidades do próprio grupo, alegando que, por não haver mudança de posse, não se caracteriza a circulação de mercadorias. As alíquotas do imposto são seletivas em função da essencialidade dos produtos ou serviços. A incidência do ICMS pago é reduzida se o produto for elaborado nas Regiões Sul e Sudeste e vendido nas Regiões Norte, Nordeste e Centro-Oeste. Além disso, as alíquotas para operações internas ao Estado possuem um valor maior que as interestaduais.

A isenção do ICMS para operações internas constitui uma vantagem de grande impacto no custo final da semente, já que incide no preço do produto final, que é alto. Dessa forma, ela estimula a produção e venda do produto no próprio Estado. No entanto, a diferenciação das alíquotas interesta- duais para operações com origem nas Regiões Sul e Sudeste e destino nas Regiões Norte, Nordeste e Centro-Oeste, adiciona um trade-off entre distância e vantagem fiscal nas decisões logísticas. Para ilustrar esse impacto, apresenta-se o seguinte exemplo. O custo de transporte é de R\$ 0,0988/ t.km, extraído do site do Sifreca para o período de 23/10 a 26/11/2004 (SIFRECA, 2004). Considerou-se o custo do farelo de soja ensacado, já que não havia o do milho ensacado, e o milho a granel não foi considerado pelo fato de embarque e desembarque serem bastante diferentes. $\mathrm{O}$ preço do produto é de $\mathrm{R} \$ 100,00$ por saco de $20 \mathrm{~kg}$, um preço médio, levando em conta as diferenças entre os tipos de sementes. Verificou-se o custo de transporte mais impostos para quatro rotas cujas origens são regiões produtoras de grãos (Tabela 1).

A Figura 2 mostra a distância da rota confrontada com o percentual do valor pago com ICMS. Nela percebe-se um aumento praticamente linear da distância, enquanto que, para o ICMS, há uma redução drástica entre as rotas com origem nas Regiões Sul ou Sudeste e destino na Região CentroOeste versus a rota com origem e destino no Centro-Oeste. Já a Figura 3 mostra o custo unitário de transporte e o de ICMS comparados lado a lado no gráfico de barras. O custo total e o da opção com menor distância estão ilustrados no gráfico de linhas.

Analisando a Figura 3, verifica-se que com uma distância inferior à de SP (Barretos) a MT, ou seja, uma distância até a ordem de $500 \mathrm{~km}$, o custo de ICMS é superior ao custo de transporte. No caso da saída de Londrina (PR), o custo de transporte é praticamente o mesmo de ICMS, ainda assim, o custo total é menor que o utilizando a menor distância, ou seja, partindo de Rio Verde (GO). Em algum ponto entre Londrina (PR) e Chapecó (SC), uma distância de 1.640 km de Cuiabá (MT), ocorre o ponto em que o custo total das rotas (transporte mais ICMS) é igual à rota de mínima distância. Esse ponto é caracterizado no gráfico pela intersecção da reta de custo total com a de mínimo custo. A partir desta distância, o custo de transporte passa a ser tão alto que a vantagem na alíquota de ICMS em relação ao Estado de

Tabela 1: Rotas consideradas.

\begin{tabular}{|c|c|c|c|}
\hline ROTA & ORIGEM & DESTINO & DISTÂNCIA (km) \\
\hline GO-MT & Rio Verde & Cuiabá & 696 \\
\hline MG-MT & Uberlândia & Cuiabá & 1.045 \\
\hline SP-MT & Barretos & Cuiabá & 1.212 \\
\hline PR-MT & Maringá & Cuiabá & 1.338 \\
\hline SC-MT & Chapecó & Cuiabá & 1.671 \\
\hline RS-MT & Passo Fundo & Cuiabá & 1.856 \\
\hline
\end{tabular}

Fonte: Distâncias extraídas do mapa do Guia 4 Rodas. 
GO passa a não ser relevante no custo total. O mínimo custo total ocorre, portanto, quando o produto é entregue a partir de Uberlândia.

\section{MODELAGEM DO PROBLEMA}

Conforme mencionado, não foram encontrados estudos na literatura aplicando modelos de programação matemática para apoiar decisões na produção e logística de sementes de milho. Além disso, a modelagem aqui proposta inclui uma parcela do custo tributário na função objetivo, neste caso o ICMS, não utilizada comumente nos problemas de planejamento da produção e logística. O estudo em Yoshizaki (2002) sugere que custos fiscais devem ser considerados para apoiar decisões logísticas. A seguir, apresentam-se algumas hipóteses admitidas para o modelo.

Figura 2: Distância X percentual do valor pago com ICMS.

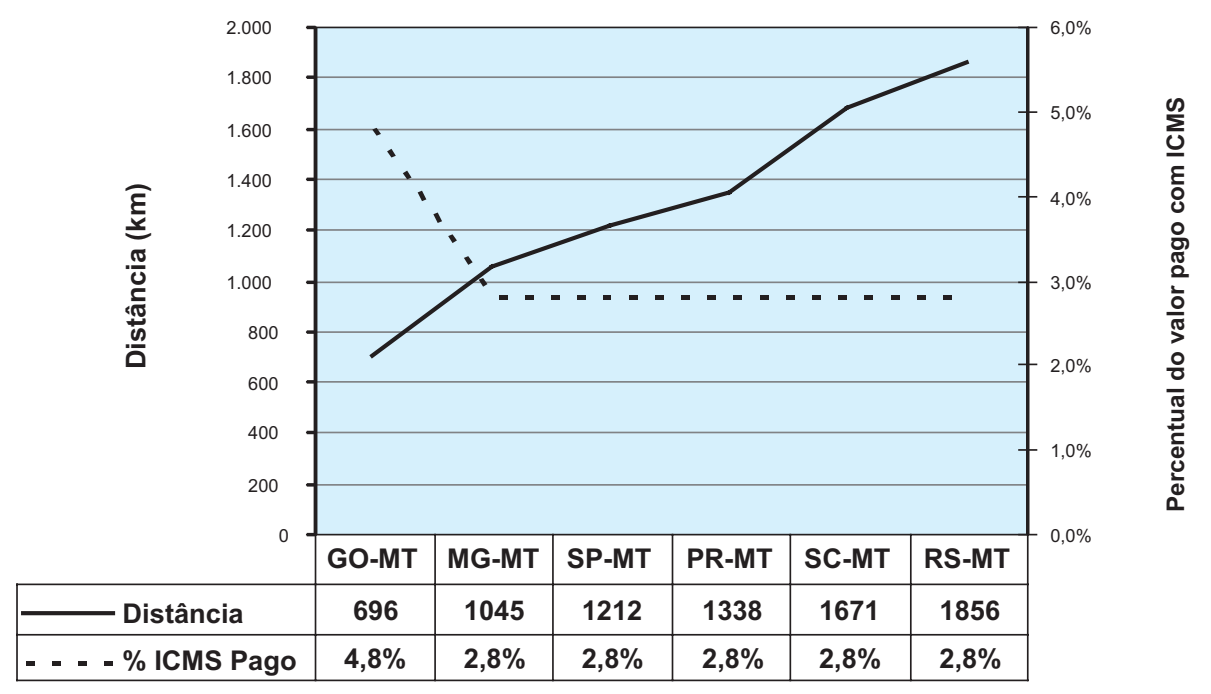

Figura 3: Custo de Transporte $\mathrm{X}$ custo de ICMS.

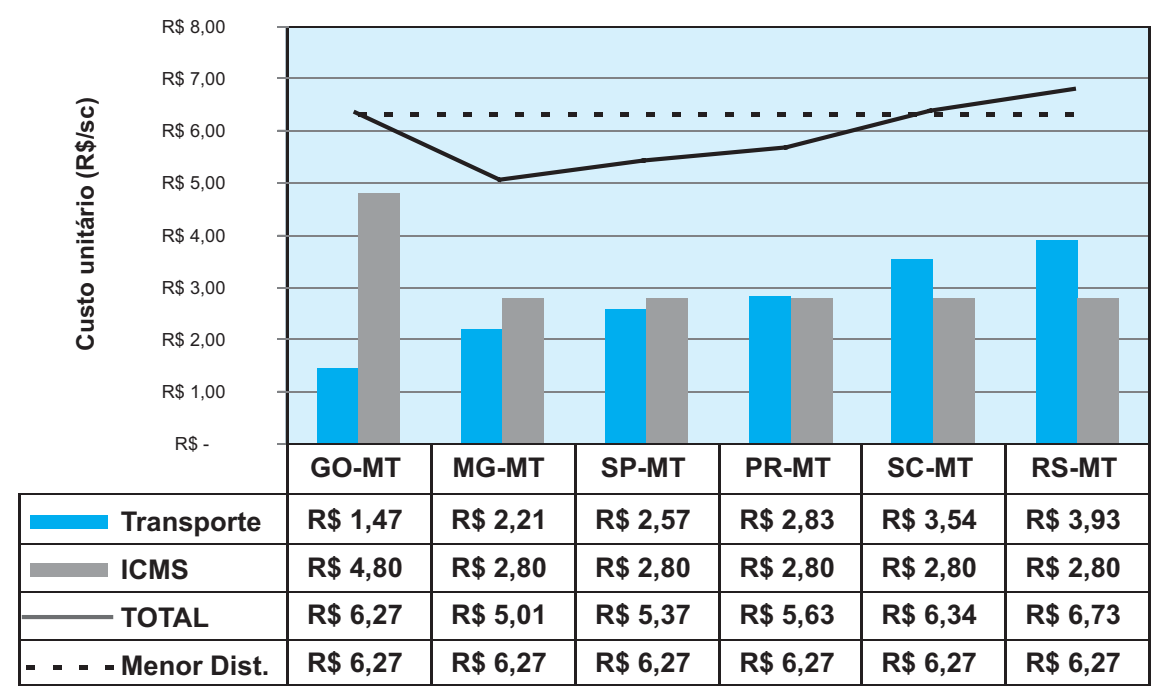




\section{Hipóteses admitidas}

A Figura 4 mostra um modelo esquemático do problema baseado em empresas do setor estudado. Tipicamente, o horizonte de planejamento do modelo é de um ano (safra de abril a março do ano seguinte), com períodos mensais. Considera-se a produção agrícola irrigada e em sequeiro com as devidas produtividades, a colheita e preparo da matéria-prima em espigas e em grãos, a armazenagem em silo, contemplando a transferência entre UBSs, o beneficiamento, contemplando a transferência de semiprocessado entre UBSs, a armazenagem em depósito, contemplando a transferência de produto acabado entre depósitos e $\mathrm{o}$ atendimento da demanda. Entretanto, algumas delimitações são feitas neste trabalho para simplificação do modelo e do método de resolução. As hipóteses admitidas estão representadas na Figura 4 e são listadas nas seções seguintes.

\section{N cenário 2, $R \$ 40.000$ seria a quantia gasta no chamado "turismo fiscal".} de transporte.

neficiamento. Do silo, é transportado e entra direto para o beneficiamento. Esta simplificação não afeta os benefícios do modelo, já que influencia situações em que o produto de um mesmo campo é transferido na forma de grãos secos para mais de uma UBS. Esta situação não é desejável no momento do planejamento, pois envolve custos adicionais

\section{Hipótese 3: Transferência de produtos semiprocessados}

A transferência de produtos semiprocessados entre UBSs após a classificação não será considerada, pois se pressupõe que esta operação está representada pela transferência de grãos no momento anterior ao beneficiamento. Essa última simplificação seria inapropriada caso fosse possível tratar a demanda por produto e por tamanho do grão (peneira). Entretanto, como a previsão de peneiramento é difícil para as empresas (CARNEIRO et al. 2001), este detalhamento não é de maior interesse.

\section{Hipótese 4: Tempos de setup}

Os tempos de setup de produção serão

\section{Hipótese 1: Decisão do plantio}

O principal recorte diz respeito à decisão de plantio. Para este tipo de decisão seria necessária a inclusão de variáveis binárias, indicando o plantio do campo com determinado produto em um determinado período, além do tipo de colheita. Por exemplo, para um plano com 10 produtos, 10 períodos, 30 campos de produção e 2 tipos de colheita, seriam necessárias cerca de 6.000 variáveis binárias, o que possivelmente tornaria o modelo de programação matemática de difícil solução exata dentro de um tempo computacional considerado aceitável. A relaxação da integralidade dessas variáveis poderia resultar no fracionamento exagerado das áreas de plantio, o que não poderia ser atendido na prática, pois induz problemas de contaminação durante o cruzamento no processo de hibridação. Sendo assim, considera-se que o plano de produção está baseado em uma programação de colheita a priori, ou seja, supõe-se que as áreas de plantio já estejam definidas. Esta hipótese não compromete os benefícios do modelo em termos da escolha do fluxo de custo mínimo para o escoamento da produção agrícola à demanda, em especial quando a empresa aumenta a abrangência de seu mercado, o número de UBSs, o número de produtos e o Estado diversifica suas políticas de isenção tributária de ICMS.

\section{Hipótese 2: Transferência de grãos secos}

Para a simplificação das análises dos resultados, considera-se que a transferência de grãos entre UBSs só pode acontecer uma vez, ou seja, o material sai do preparo da matéria-prima e vai diretamente para o silo da UBS de be- desconsiderados por simplicidade, já que há bastante incerteza quanto ao momento da colheita do híbrido e a quantidade a ser colhida. No prazo de um mês, por exemplo, pode haver chuva em excesso, atrasando a colheita devido ao aumento da umidade da semente e à impossibilidade de entrar na lavoura por causa da dificuldade de acesso e compactação do solo. Também se houver falta de chuva ou uma manifestação de praga nesse período, pode haver uma quebra de safra, reduzindo a utilização da capacidade da UBS. Como o tempo de setup médio é de menos de um dia, conforme informado pela Empresa A, ele passa a ser pouco relevante dentro do período de um mês, podendo ser representado por um percentual de aproveitamento de tempo no período. Portanto, esta simplificação não compromete os resultados do modelo para apoiar decisões táticas de médio-longo prazo.

\section{Hipótese 5: Transferência entre depósitos}

$\mathrm{Na}$ distribuição, o produto vai do beneficiamento diretamente para o depósito da UBS. Em seguida, pode permanecer no depósito para atender à demanda dos períodos seguintes, ou ser enviado para uma região de demanda. Não foi considerada a transferência de produto acabado entre depósitos. Assim como no caso da transferência de grãos secos, esta situação não é desejável no momento do planejamento, pois envolve custos adicionais de transporte.

\section{Apresentação do modelo}

Com os recortes delimitados na seção anterior e com base na literatura clássica de pesquisa operacional, o problema em 
questão pode ser classificado como um problema de dois estágios (níveis), sendo o primeiro deles relativo às operações de colheita, transporte e preparo da matéria-prima e o outro, às de transporte e beneficiamento. Há possibilidade de transbordo entre os estágios, representada pelas transferências de grãos após o preparo da matéria-prima. Os recursos dos estágios são limitados, tratando-se, portanto, de restrições de capacidade. Como são consideradas mais de uma UBS em diferentes locais, pode ser caracterizado como um problema multiplantas. Além disso, são considerados mais de um produto (problema multiproduto), e mais de um período no horizonte de decisão (problema multiperíodo). Conforme mencionam Hax \& Candea (1984) e Nahmias (1995), o enfoque quanto ao período de decisão do problema pode ser considerado como Plano Agregado, olhando para decisões táticas.

\section{Índices}

O índice $h$ representa cada híbrido, ou seja, os produtos da empresa de sementes. É recomendado que cada produto seja considerado individualmente, pois a demanda é direcionada para o produto, já que o cliente está interessado em características específicas como a adequação à região. O plantio e o gerenciamento da lavoura também são feitos especificamente para o produto. Além disso, os preços de venda são significativamente diferentes entre os produtos de um mesmo tipo de híbrido. Os tipos de colheita são representados pelo índice $m$, e são fixos: espiga e grão. As regiões de produção agrícola são caracterizadas pelo índice $i$. Recomenda-se que as regiões sejam divididas de tal forma a caracterizar as rotas cujos custos de transporte sejam diferenciados.

\section{nom base nos experimentos realizados, as expectativas para todos os cenários foram contempladas.}

As UBSs são representadas pelo índice $j$. As regiões de demanda são representadas pelo índice $k$. O nível de agregação delas deve ser suficiente para caracterizar ao menos as diferenças fiscais dos Estados. Recomenda-se, também, desagregar as regiões de tal forma que se possam caracterizar as diferenças nos custos de transporte. Os períodos de comercialização são representados pelo índice $t$. Os períodos devem ser suficientemente grandes para não serem influenciados pelos tempos de setup de produção, e pequenos de forma a evitar processamento de vários campos em um curto período de tempo. A unidade de análise utilizada no modelo é um saco de $20 \mathrm{~kg}$, embalagem em que é comercializado o produto final.

Figura 4: Modelo esquemático do problema.

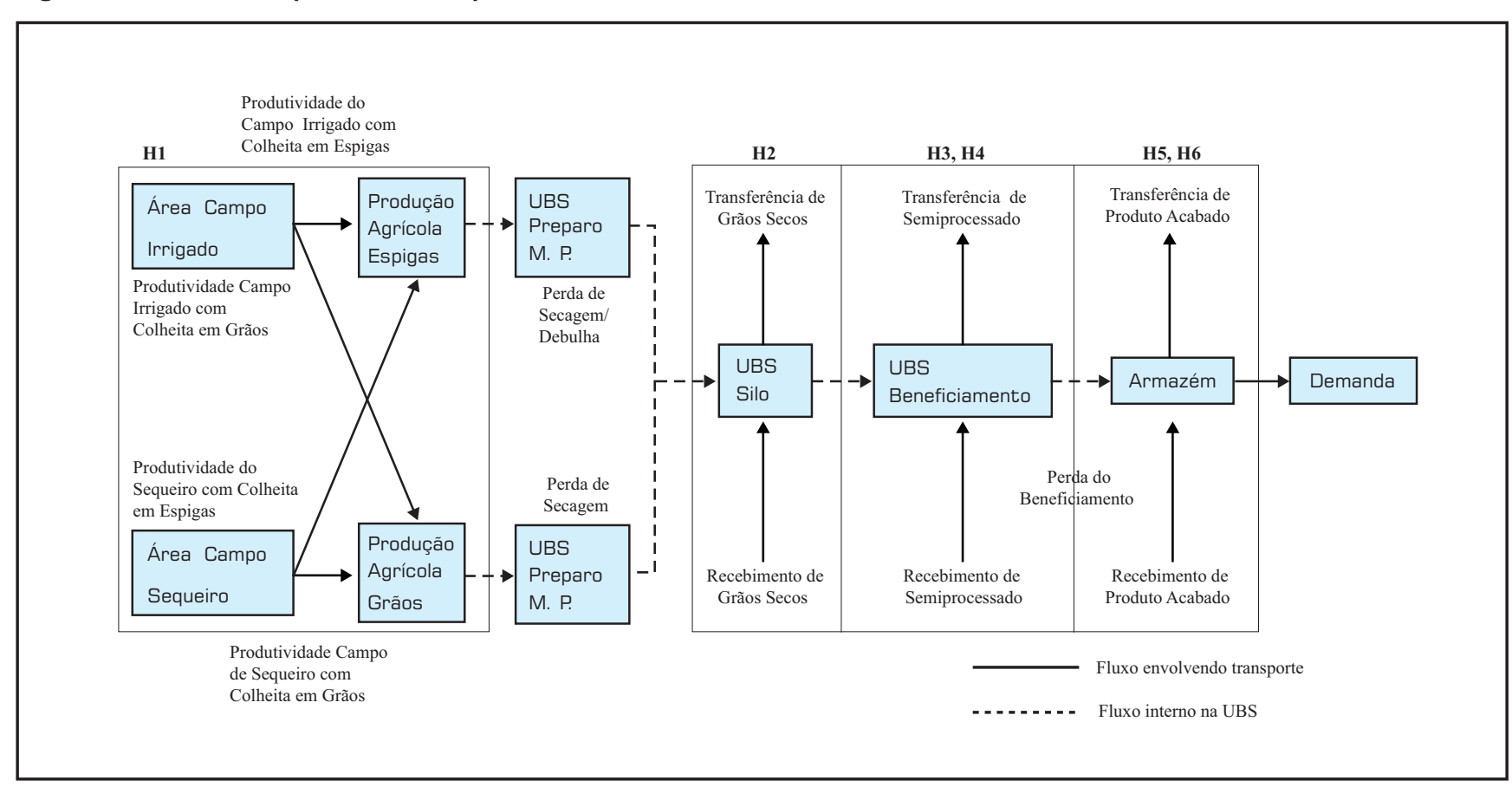




\section{Dados de entrada}

Os parâmetros de entrada do modelo seguem abaixo:

\begin{tabular}{|c|c|}
\hline$C t r_{i, j, m, t}$ & $\begin{array}{l}\text { custo de frete para transportar uma tonelada do tipo de colheita } m \text { do campo } i \text { para a UBS } j \text { no } \\
\text { período } t \text { [em } \mathrm{R} \$ / \text { tonelada]. }\end{array}$ \\
\hline$C t f_{j, j, t}$ & $\begin{array}{l}\text { custo de frete para transportar uma tonelada da UBS } j \text { para a UBS jp no período } t \text { [em R } \$ / \\
\text { tonelada]. }\end{array}$ \\
\hline$C e_{j, k, t}$ & $\begin{array}{l}\text { custo de frete para transportar um saco de } 20 \mathrm{~kg} \text { da UBS } j \text { para a região de demanda } k \text { no período } \\
t \text { [em } \mathrm{R} \$ / \mathrm{sc} \text { ]. }\end{array}$ \\
\hline $\operatorname{ICMS}_{j, k}$ & tarifa de ICMS paga pela venda de um saco de $20 \mathrm{~kg}$ da UBS $j$ na região de demanda $k$. \\
\hline$P_{h, k}$ & preço de venda do produto $h$ na região de demanda $k$ [em $\mathrm{R} \$ / \mathrm{sc}$ ]. \\
\hline$C p_{j, m}$ & custo de preparo da matéria-prima para o tipo de colheita $m$ na UBS $j$ [em $\mathrm{R} \$ / \mathrm{sc}$ ]. \\
\hline$C b_{j}$ & custo de beneficiamento na UBS $j$ [em $\mathrm{R} \$ / \mathrm{sc}$ ]. \\
\hline $\mathrm{EGSecoO}_{h, j}$ & Quantidade inicial do híbrido $h$, armazenada como grãos secos na UBS $j$ [em sacos]. \\
\hline EPFinalO $_{h, j}$ & Quantidade inicial do híbrido $h$, armazenada como produto final na UBS $j$ [em sacos]. \\
\hline EGSecof $_{h}$ & quantidade final do híbrido $h$, armazenada como grãos secos [em sacos]. \\
\hline EPFinalf $_{h}$ & quantidade inicial do híbrido $h$, armazenada como produto final [em sacos]. \\
\hline $\operatorname{Dem}_{h, k, t}$ & quantidade demandada do híbrido $h$, na região mercadológica $k$ e no período $t$ [em sacos]. \\
\hline $\mathrm{PCol}_{h, i, m, t}$ & plano de colheita do híbrido $h$, com o tipo de colheita $m$, no campo $i$ e no período $t$ [em sacos]. \\
\hline$\%$ RendPrep ${ }_{m}$ & rendimento no preparo de matéria-prima para o tipo de colheita $m$. \\
\hline$\%$ RendBen & rendimento no beneficiamento. \\
\hline TxPrep $_{j, m}$ & taxa de preparo da matéria-prima na UBS $j$ do tipo de colheita $m$ [em sacos por dia]. \\
\hline CapSilo $_{j}$ & capacidade de armazenagem em silo na UBS $j$ [em sacos por dia]. \\
\hline TxBen $_{j}$ & taxa de preparo de beneficiamento na UBS $j$ [em sacos por dia]. \\
\hline CapDep & capacidade de armazenagem em depósito na UBS $j$ [em sacos por dia]. \\
\hline TurBen $_{j}$ & horas de turno de beneficiamento na UBS $j$ [em horas por dia]. \\
\hline NDias $_{t}$ & número de dias no período $t$ [em dias]. \\
\hline
\end{tabular}

\section{Variáveis de decisão}

A listagem das variáveis de decisão do modelo segue abaixo:

\begin{tabular}{|c|c|}
\hline$X_{h, i, j, m, t}$ & $\begin{array}{l}\text { quantidade do híbrido } h \text {, colhida com o tipo de colheita } m \text { no campo } i \text {, transportada para a UBS } j \text { e } \\
\text { nela preparada no período } t \text { [em sacos]. }\end{array}$ \\
\hline$Y_{h, j, j p, t}$ & $\begin{array}{l}\text { quantidade do híbrido } h \text {, preparada na UBS } j \text { e transportada para ser beneficiada na UBS jp no } \\
\text { período } t \text { [em sacos]. }\end{array}$ \\
\hline$Z_{h, j, k, t}$ & $\begin{array}{l}\text { quantidade do híbrido } h \text {, beneficiada na UBS } j \text { e transportada para a região de demanda } k \text { no } \\
\text { período } t \text { [em sacos]. }\end{array}$ \\
\hline $\mathrm{EGSeco}_{h, j, t}$ & quantidade do híbrido $h$, armazenada como grãos secos na UBS $j$ e no período $t$ [em sacos]. \\
\hline inal ${ }_{h, j}$ & antidade do híbrido $h$, armazenada como produto final na UBS $j$ e no período $t$ [em sacos]. \\
\hline
\end{tabular}

Para entendimento dessas variáveis foram feitos dois esquemas: um mostrando um recorte espacial para um único período (Figura 5), e outro com um recorte temporal isolando uma UBS (Figura 6). A Figura 5 mostra as I regiões de produção agrícola, cada uma com sua programação de colheita. O que foi produzido no campo pode ser enviado para qualquer uma das $J$ UBS que realizam o preparo da matéria-prima para o tipo de colheita específico. Terminado o preparo, o material vai para o silo da UBS. Dele, o milho pode ser transferido para ser beneficiado em qualquer uma das $J$ UBSs. Para simplificação do modelo, o milho depois de transferido entra diretamente em processo. Depois de beneficiado, o milho vai para o depósito da UBS. Do depósito, é enviado para as $K$ regiões de demanda. A Figura 5 mostra que no estágio 1 as UBSs podem 
receber milho das $I$ áreas com programação de colheita, sendo possível estocá-lo e beneficiá-lo na própria UBS, ou enviar para as $J$ UBSs de beneficiamento. Já o estágio 2 pode receber sementes preparadas nas $J$ UBSs e enviar para as $K$ regiões de demanda, ou, se necessário, estocar em depósito.

Já a Figura 6 mostra um recorte temporal, centrado no período $t$. Percebe-se que as operações do estágio 1 , colhei- ta, transporte e preparo da matéria-prima, devem acontecer dentro do mesmo período, representando um sistema de produção empurrado. A matéria-prima preparada pode aguardar o momento de sua necessidade de duas formas: como grão seco em silos ou big-bags (estágio 1), ou em depósitos como produto acabado (estágio 2). Qualquer uma destas maneiras pode ser puxada pela demanda.

Figura 5: Recorte espacial do problema proposto.

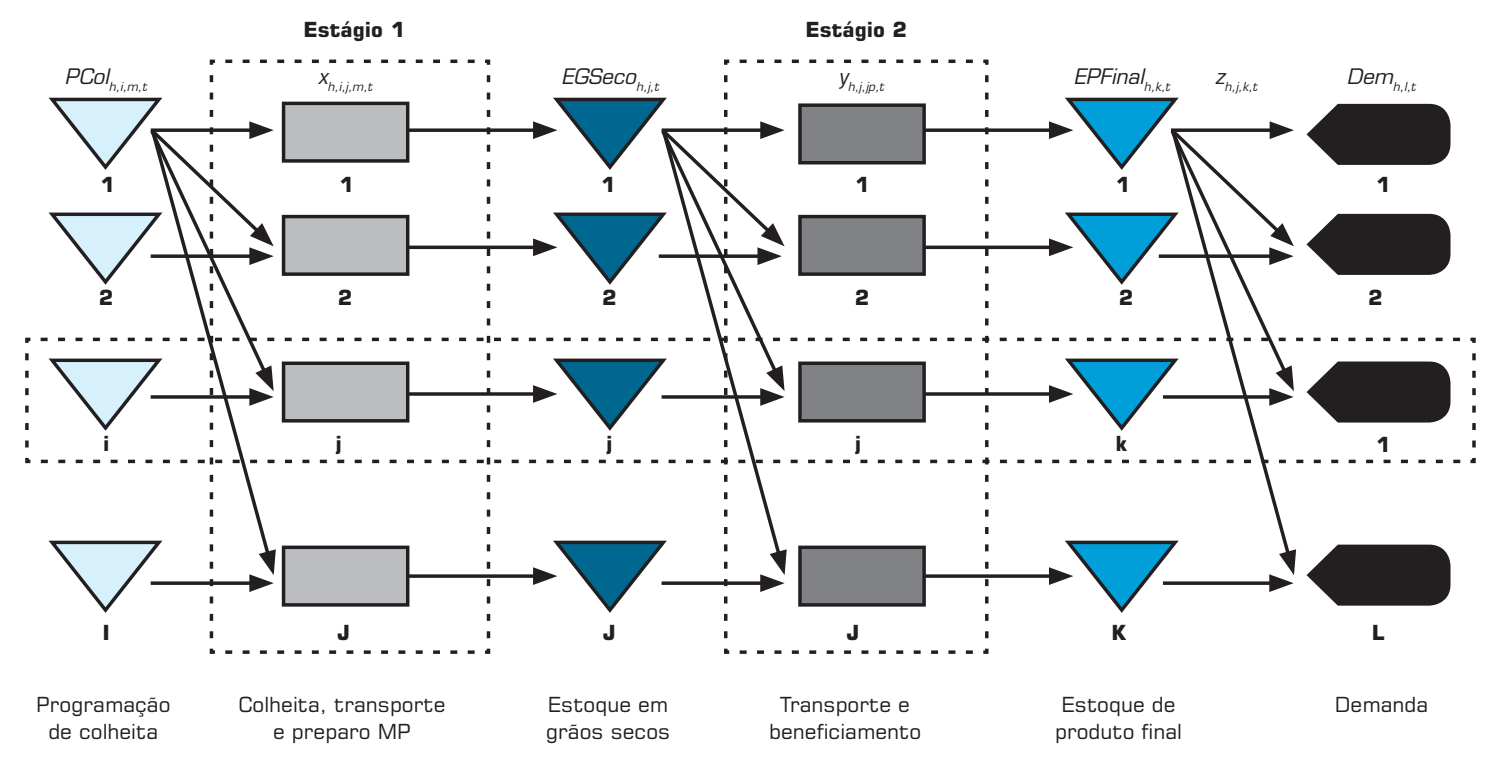

Figura 6: Recorte temporal do problema proposto.

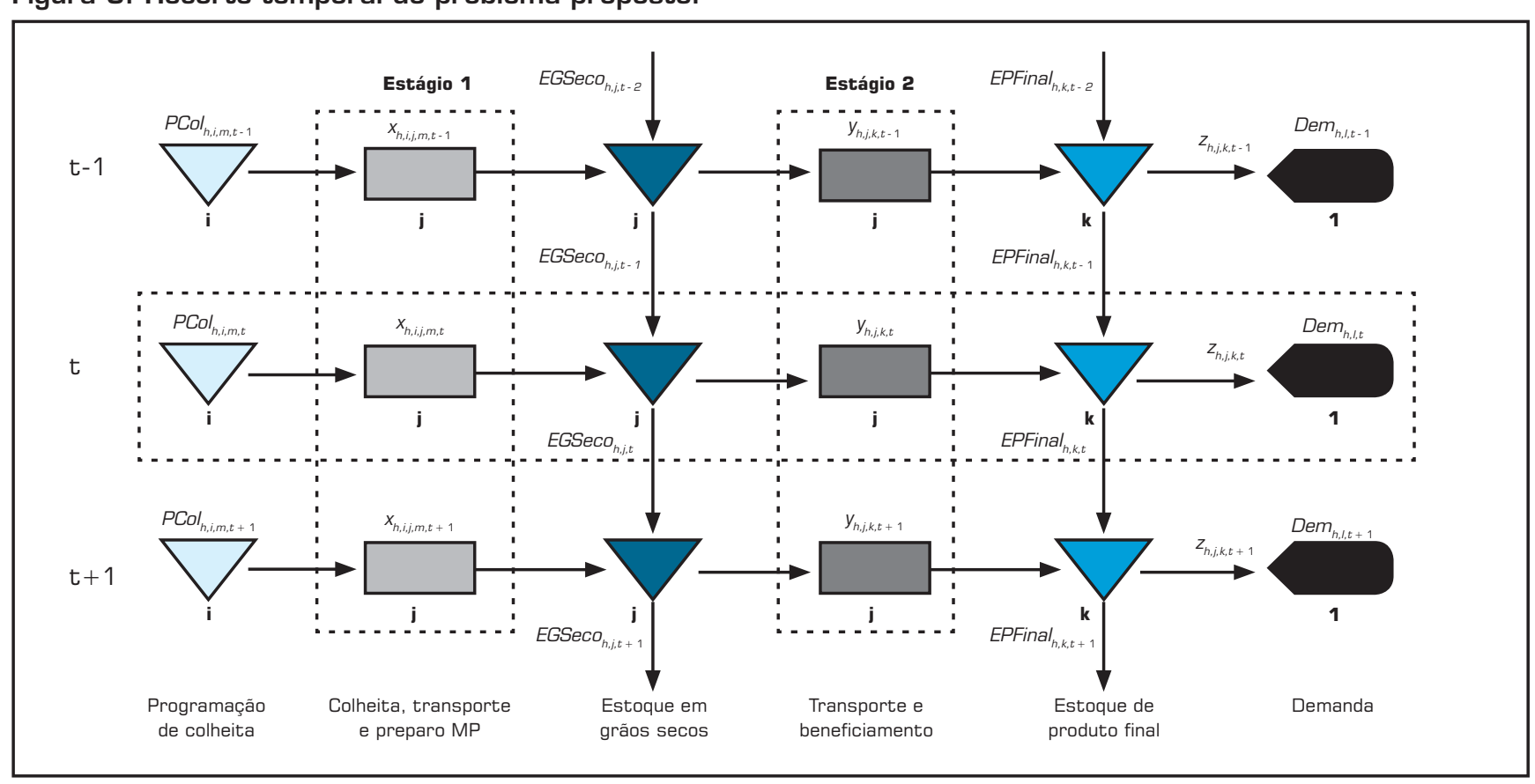




\section{Função objetivo}

A função objetivo do modelo busca minimizar o custo logístico total (CT) e é composta pelos custos de: transporte e preparo da matéria-prima, transferência de grãos secos entre UBSs, beneficiamento e entrega, composto pelo custo de transporte e de ICMS, ou seja,

\section{$C T=$ Transporte $M P+$ Preparo $M P+$ Transferência UBSs + Beneficiamento + Entrega}

onde,

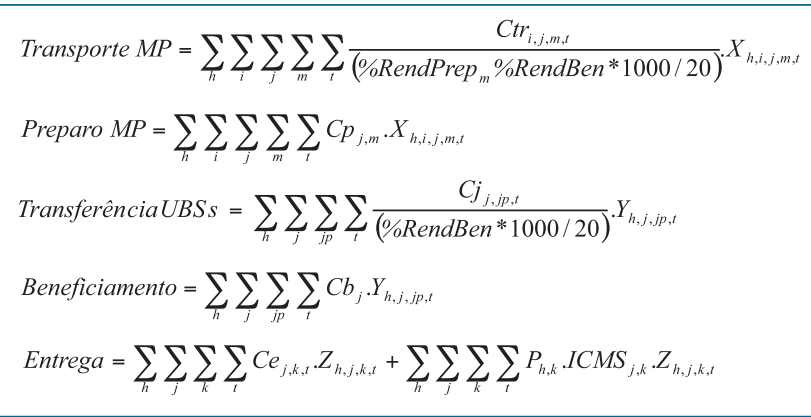

As constantes 1000/20 nestas expressões correspondem à conversão dos custos de toneladas para sacos. Cabe ressaltar que não foram considerados em $C T$ os custos da matéria-prima, já que o plano de colheita já está definido; de armazenagem, uma vez que não se admitiu a possibilidade de transferir o produto buscando apenas a armazenagem mais viável sem necessariamente haver beneficiamento; de outros impostos como o IPI, PIS, COFINS e ISS, pelo fato deles poderem ser representados pelos custos de preparo e beneficiamento; bem como o próprio ICMS nas outras etapas de transporte, pois a parcela mais custosa desse imposto é na entrega, quando o valor do produto atinge o preço de venda.

\section{Restrições}

As restrições do modelo podem ser divididas entre as de balanceamento de massa, de limitação de capacidade e de não negatividade das variáveis. A seguir elas são apresentadas e discutidas. As restrições referentes ao balanceamento de massa são as seguintes:

\begin{tabular}{|c|c|}
\hline$P \operatorname{Col}_{h, i, m, t}=\sum X_{h, i, j, m, t} \quad$ parah $=1 . . H, i=1 . . I, m=1 . . M, t=1 . . T$ & (1) \\
\hline $\begin{aligned} \sum_{t} \sum_{m} X_{h, i, j, m, t}+E G S e c o_{h, j, t-1}=\sum_{j p} Y_{h, j, j, t, t}+E G S e c o_{h, j, t} \\
\quad \text { para } h=1 . . H, j=1 . . J, t=2 . . T\end{aligned}$ & (2) \\
\hline $\begin{array}{r}\sum_{i} \sum_{m} X_{h, i, j, m, 1}+E G S e c o 0_{h, j}=\sum_{j p} Y_{h, j, j p, 1}+E G S e c o_{h, j, 1} \\
\text { parah }=1 . . H, j=1 . . J\end{array}$ & (3) \\
\hline
\end{tabular}

$$
\begin{aligned}
& \sum_{j, p} Y_{h, j, j p, t}+\text { EPFinal }_{h, j, t-1}=\sum_{k} Z_{h, j, k, t, t}+\text { EPFinal }_{h, j, t} \\
& \operatorname{para} h=1 . . H, j=1 . . J, t=2 . . T \\
& \sum_{p} Y_{h, j, j p, 1}+\text { EPFinal }_{h, j}=\sum_{k} Z_{h, j, k, 1}+\text { EPFinal }_{h, j, 1} \\
& \text { parah }=1 . . H, j=1 . . J \\
& \sum Z_{h, j, k, t}=\operatorname{Dem}_{h, k, t} \quad \text { para } h=1 . . H, k=1 . . K, t=1 . . T \\
& \sum \text { EPFinal }_{h, j, T} \geq \text { EPFinalf }_{h} \quad \text { para } h=1 . . H
\end{aligned}
$$

\begin{tabular}{|c|c|c|}
\hline$\sum_{h} \sum_{i} X_{h, i, j, m, t} \leq$ CapPrep $_{j, m}$. NDias $_{t}$ & para $j=1 . . J, m=1 . . M, t=1 . . T$ & (8) \\
\hline$\sum_{h} \sum_{j p} Y_{h, j, j p, t} \leq$ CapBen $_{j}$. NDias $_{t}$ & para $j=1 . . J, t=1 . . T$ & (9) \\
\hline$\sum_{h}$ EGSeco $_{h, j, t} \leq$ CapSilo $_{j}$ & para $j=1 . . J, t=1 . . T$ & (10) \\
\hline$\sum_{h}$ EPFinal $_{h, j, t} \leq$ CapDep $_{j}$ & para $j=1 . . J, t=1 . . T$ & $(11)$ \\
\hline
\end{tabular}

\begin{tabular}{|c|c|c|}
\hline$X_{h, i, j, m, t} \geq 0$ & para $h=1 . . H, i=1 . . I, j=1 . . J, m=1 . . M, t=1 . . T$ & $(12)$ \\
\hline$Y_{h, j, j p, t} \geq 0$ & para $h=1 . . H, j=1 . . J, j p=1 . . J, t=1 . . T$ & $(13)$ \\
\hline$Z_{h, j, k, t} \geq 0$ & para $h=1 . . H, j=1 . . J, k=1 . . K, t=1 . . T$ & $(14)$ \\
\hline$E G S e c o_{h, j, t} \geq 0$ & para $h=1 . . H, j=1 . . J, t=1 . . T$ & $(15)$ \\
\hline EPFinal $_{h, j, t} \geq 0$ & para $h=1 . . H, j=1 . . J, t=1 . . T$ & $(16)$ \\
\hline
\end{tabular}

Já as restrições referentes às limitações de capacidades são as seguintes:

As restrições de não negatividade são:

A equação (1) garante que cada produto $h$ que compõe o plano de colheita de cada região agrícola $i$ no período $t$ de acordo com a tecnologia de colheita $m$ seja transportado e o preparo da matéria-prima nas UBSs seja realizado. A equação (2) garante que cada produto $h$ será beneficiado em cada UBS $j$ no período $t$, ou guardado em silo para o próximo período $t$. A equação (3) é um caso particular de (2) para o primeiro período $t=1$, em que o estoque do período anterior é o estoque inicial do horizonte de decisão, ou seja, um parâmetro de entrada ao invés de uma variável. A equação (4) garante que o produto $h$ será entregue para as regiões de demanda no período $t$, ou armazenado em depósito na UBS $j$ para o próximo período. Semelhantemente à equação (3), a equação (5) é a (4) para o caso particular do primeiro período $t=1$.

A equação (6) garante que a demanda de cada híbrido $h$ em cada região $k$ e cada período $t$ seja atendida pelo que foi 
entregue das $J$ UBSs. Já a inequação (7) garante que o estoque final de cada híbrido $h$ seja maior ou igual ao estoque final estabelecido como parâmetro. A inequação (8) garante que a matéria-prima $m$, preparada tanto em grãos como em espigas, não ultrapassará a limitação de capacidade da UBS $j$ no período $t$. A inequação (9) tem função semelhante à (8), mas para o caso da capacidade de beneficiamento. As inequações (10) e (11) garantem que os estoques de grãos secos e produto acabado que passarão para o período seguinte não ultrapassarão as limitações de capacidade de armazenagem em cada UBS $j$ no período $t$. As inequações (12), (13), (14), (15) e (16) impõem que as variáveis de decisão, $X, Y, Z$, EGSeco e EPFinal sejam não-negativas.

O modelo foi implementado na linguagem de modelagem GAMS (versão 2.0.10.0), que oferece diversos solvers para a resolução do modelo (BROOKE et al., 1992; KIUP, 1993). Dentre eles, foi utilizado o CPLEX (versão 7.0.0), bastante conhecido na literatura por resolver eficientemente problemas de programação linear utilizando algoritmos primal e dual simplex modificados.

\section{RESULTADOS COMPUTACIONAIS}

Nesta seção é considerada uma rede de sementes de milho com um número de variáveis reduzido, mas capaz de ilustrar os trade-offs envolvidos no modelo apresentado. Este exemplo de rede baseia-se nos dados coletados na Empresa A, referentes à demanda para a safra 2003/2004. Foram adotados os meses de junho, julho, agosto e setembro da referida safra. Além disso, foram considerados quatro produtos da carteira de pedidos da empresa: um simples, um duplo, um triplo e uma variedade. A Figura 7 apresenta a configuração da rede considerada, que é uma simplificação da Empresa A. A rede possui três regiões de produção agrícola, uma no Estado de São Paulo, na região de Barretos, outra em Minas Gerais, na região de Ituiutaba, e outra em Goiás, na região de Rio Verde. São consideradas também três UBSs: uma em São Paulo, na região de Barretos, outra em Minas Gerais, na região de Ituiutaba, e outra em Goiás, na região de Rio Verde. As regiões de demanda são agrupadas em cinco Estados: SP, MG, GO, RS e MT.

As UBSs possuem equipamentos para o preparo da matéria-prima e o beneficiamento e estão localizadas próximas às regiões de produção agrícola. As capacidades de preparo de espigas, grãos e de beneficiamento são dadas na Tabela 2. As Tabelas 3, 4 e 5 apresentam dados de custos que foram modificados para proteger interesses da empresa - estas alterações mantiveram a proporcionalidade dos custos para não tornar a análise pouco realista. A Tabela 3 mostra o custo de transporte de matéria-prima em $\mathrm{R} \$$ / tonelada. Como se pode observar na Tabela 3, o transporte em espigas é mais caro devido ao fato de a carroceria ser especial e a densidade de carga, mais baixa devido à presença do sabugo. A Tabela 4 apresenta o custo de transporte entre as UBSs em R \$/ tonelada. A Tabela 5 apresenta os custos de entrega para as regiões de demanda consideradas. O custo de entrega a MT foi questionado durante o levantamento de dados, devido ao fato de ser o mesmo para as três distintas origens: as UBSs de SP, MG e GO. Neste caso, o especialista da Empresa A argumentou que os custos de frete são realmente equivalentes.

Figura 7: Configuração da rede.

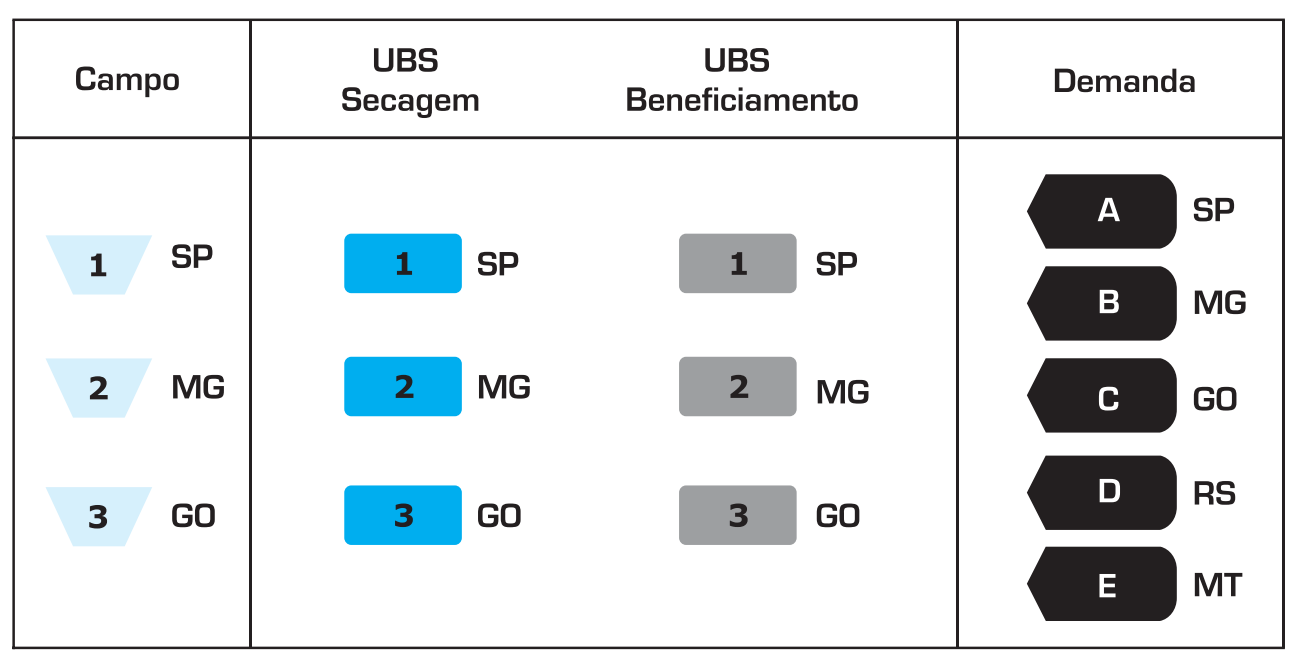




\section{Análise de cenários}

Com base na rede apresentada na seção anterior, foram gerados seis cenários variando os custos considerados na função objetivo e as condições de limitação da capacidade. Para mais detalhes destes cenários, o leitor pode consultar JUNQUEIRA (2006). No cenário 1, não são considerados os custos de ICMS, preparo e beneficiamento e há sobrecarga em algumas UBSs para suprir a demanda em determinados períodos. Sendo assim, espera-se que em alguns casos as sementes de milho não sejam processadas nas UBSs de menor custo de transporte, pelo fato de elas estarem sobrecarregadas. Por meio dos custos marginais é possível avaliar os custos de oportunidade para o investimento em unidades de capacidade adicionais, já que alguns recursos apresentam utilização de $100 \%$ da capacidade.

No cenário 2, a capacidade das UBSs de preparo de espigas e de beneficiamento é ampliada, seguindo as oportunidades apontadas pelos custos marginais analisados no cenário 1. Assim como no anterior, não estão sendo considerados os custos de preparo, beneficiamento e ICMS. Espera-se que a matéria-prima não seja enviada diretamente para a UBS mais próxima do campo quando a demanda acontecer a uma longa distância do local de produção agrícola. Por fim, deseja-se verificar a economia de custo obtida em relação ao cenário 1 com o investimento em capacidade.

Tabela 2: Capacidade das UBSs (em sacos por dia).

\begin{tabular}{|c|c|c|c|}
\hline UNIDADES & PREPARO ESPIGAS & PREPARO GRÃOS & BENEFICIAMENTO \\
\hline UBS_SP & 793 & 2.067 & 1.615 \\
\hline UBS_MG & 534 & 3.876 & 1.413 \\
\hline UBS_GO & 1.428 & 4.134 & 1.777 \\
\hline
\end{tabular}

Tabela 3: Custo de transporte da matéria-prima em $\mathbf{R} \$$ /tonelada.

\begin{tabular}{|c|c|c|c|c|c|c|}
\cline { 2 - 8 } \multicolumn{1}{c|}{} & \multicolumn{3}{c|}{ DESTINO } \\
\cline { 2 - 8 } & \multicolumn{3}{c|}{ ESPIGAS } & UBS_SP & UBS_ME & UBS_EO \\
\hline ORIGEM & UBS_SP & UBS_MG & UBS_EO & 9 & 30 & 40 \\
\hline RA_SP & 12 & 35 & 45 & 30 & 10 & 25 \\
\hline RA_MG & 35 & 12 & 30 & 45 & 25 & 9 \\
\hline RA_GO & 60 & 30 & 12 & 45 & 9 \\
\hline
\end{tabular}

Fonte: dados coletados na Empresa A para a safra 2003/2004

Tabela 4: Custo de transporte entre UBSs em R\$/tonelada.

\begin{tabular}{|c|c|c|c|}
\cline { 2 - 4 } \multicolumn{1}{c|}{} & \multicolumn{2}{c|}{ DESTINO } & UBS_GO \\
\hline ORIGEM & UBS_SP & 30 & 45 \\
\hline UBS_SP & 0 & 0 & 25 \\
\hline UBS_MG & 30 & 25 & 0 \\
\hline UBS_GO & 45 & UBS_MG & \\
\hline
\end{tabular}

Fonte: dados coletados na Empresa A para a safra 2003/2004.

Tabela 5: Custo de entrega em $\mathrm{R} \$ / \mathrm{sc} 20 \mathrm{~kg}$.

\begin{tabular}{|c|c|c|c|c|}
\hline \multirow[b]{2}{*}{ ORIGEM } & \multicolumn{4}{|c|}{ DESTINO } \\
\hline & RD_SP & RD_MG & RD_G0 & RD_MT \\
\hline UBS_SP & 0,56 & 0,92 & 1,40 & 1,20 \\
\hline UBS MG & 0,93 & 0,72 & 1,18 & 1,20 \\
\hline UBS_GO & 1,40 & 1,15 & 0,65 & 1,20 \\
\hline
\end{tabular}

Fonte: dados coletados na Empresa A para a safra 2003/2004 
No cenário 3, foi mantida a condição de sobra de capacidade do cenário $2 \mathrm{e}$ foi inserido o custo de ICMS da forma que rege a lei deste imposto para insumos agrícolas (Influências Fiscais), ou seja, a alíquota incide sobre uma parte do valor do preço de venda do produto e há isenção do imposto para a venda do produto no mesmo Estado em que foi produzido. Dessa forma, o custo de entrega deixa de ser apenas o custo de transporte, incluindo o custo do ICMS. Pretendese, portanto, verificar a influência do custo de ICMS em um cenário em que não há interferência das restrições de capacidades. Espera-se, portanto, que haja uma reconfiguração dos fluxos, favorecendo os arcos com vantagens fiscais.

No cenário 4, é mantida a mesma configuração do cenário 3, porém considerando que a UBS de São Paulo conseguiu judicialmente uma isenção de ICMS para a transferência entre unidades. Além disso, existe uma unidade de armazenagem pertencente ao grupo na região do Rio Grande do Sul. Com essa alteração, espera-se que as entregas com destino ao Rio Grande do Sul saiam predominantemente da UBS de São Paulo e, em função disso, pode haver sobrecarga nesta UBS, devido à reconfiguração do fluxo, gerando, assim, ganhos marginais com o aumento da capacidade da UBS de São Paulo.

No cenário 5 , foram mantidas as características do cenário $4 \mathrm{e}$ foram acrescentados os custos de preparo e beneficiamento. Esta diferença de custo é provinda de diferenças na tecnologia de preparo de espigas, em que a UBS de Minas Gerais seca utilizando como insumo o sabugo de milho ao invés de gás, o qual é usado nas UBSs de São Paulo e de Goiás. O uso do sabugo gera uma economia de custo de $\mathrm{R} \$ 1,50$ por saco de $20 \mathrm{~kg}$. Com essa alteração, espera-se que o preparo de matéria-prima se concentre na UBS de Minas Gerais, podendo causar sobrecargas na UBS. Quanto ao custo adicional de beneficiamento, devido à hora da mão-de-obra ser mais cara, o custo de beneficiamento de São Paulo é R $\$ 1,00$ mais caro que nas outras unidades. Com esta alteração, espera-se que o maior custo de beneficiamento da UBS de São Paulo reduza sua utilização. Além disso, devem surgir custos marginais na UBS de Minas Gerais.
No cenário 6, foram mantidas as condições do cenário 3 . No entanto, foi retirada a vantagem conferida aos produtos agropecuários de isenção de ICMS na venda nos próprios Estados de produção da semente. Espera-se que neste cenário o comportamento do fluxo de materiais se assemelhe ao descrito por Yoshizaki (2002), ou seja, dando preferência para que os produtos vendidos tenham origem em outros Estados.

\section{Desempenho computacional}

Para todos os cenários, o modelo foi executado em um microcomputador Toshiba Satellite A10, com processador Intel-Pentium 4 de 2,20GHz, com memória RAM utilizável de 496 MB e HD de 40 GB. O modelo possui 725 equações e 865 variáveis. A Tabela 6 mostra o desempenho computacional do modelo para cada um dos cenários, divididos em três tempos: o tempo de execução do algoritmo de preparação da matriz do modelo, o tempo de geração da matriz e o tempo de execução propriamente dita, todos em segundos. Observando esta tabela, embora tenha havido uma variação considerável entre a execução do cenário 3 e 4, o tempo total para todos os casos se manteve bastante pequeno, evidenciando agilidade na resolução do modelo.

\section{Comparação dos cenários e discussões}

Nesta seção são analisados os valores dos custos da função objetivo obtidos em cada cenário, mostrados na Tabela 7. Com a análise desta tabela fica evidente que o aumento de capacidade efetuado no cenário $2 \mathrm{fez}$ com que fossem reduzidos os custos de transporte de matéria-prima e transferência. Através da análise de sensibilidade verificou-se que o aumento de uma unidade de capacidade de preparo de espigas proporciona uma economia de até $\mathrm{R} \$ 2,32$ por saco na UBS SP e R \$ 1,24 na UBS MG. Quanto ao beneficiamento, o aumento de uma unidade de processamento gera uma redução de custo de até $\mathrm{R} \$ 0,29$ por saco na UBS MG e de $\mathrm{R} \$ 0,68$ na UBS GO. O custo de entrega aumentou, mas foi inferior à redução de custo das outras parcelas.

Tabela 6: Tempos de execução do modelo para cada cenário.

\begin{tabular}{|c|c|c|c|c|}
\hline GENÁRIO & $\begin{array}{c}\text { TEMPO DO } \\
\text { PRESOLVE (S) }\end{array}$ & $\begin{array}{c}\text { TEMPO DE } \\
\text { GERAÇÄ̈0 (S) }\end{array}$ & $\begin{array}{c}\text { TEMPO DE EXEGUÇÃO } \\
\text { (S) }\end{array}$ & $\begin{array}{c}\text { TEMPO TOTAL } \\
\text { (S) }\end{array}$ \\
\hline 1 & 0,00 & 0,06 & 0,06 & 0,12 \\
\hline 2 & 0,00 & 0,07 & 0,07 & 0,14 \\
\hline 3 & 0,01 & 0,05 & 0,05 & 0,11 \\
\hline 4 & 0,00 & 0,12 & 0,12 & 0,24 \\
\hline 5 & 0,01 & 0,07 & 0,07 & 0,15 \\
\hline 6 & 0,00 & 0,07 & 0,07 & 0,14 \\
\hline
\end{tabular}


Se para esse cenário fosse utilizada a regra do envio da semente à UBS mais próxima do campo, a sobrecarga de capacidade não teria sido detectada no plano, mas apenas durante sua execução. Da mesma forma, a conveniência na transferência entre UBSs do preparo e beneficiamento não teria sido percebida com antecedência. Com a solução gerada pelo modelo, é possível alertar as UBSs com antecedência para receberem a matéria-prima que virá de regiões mais distantes ou transferida de outras unidades. Com isso, o suprimento desses materiais pode ser planejado, para evitar colheita simultânea de dois campos e minimizar a chance de misturar campos nas UBSs.

Já no cenário 3 , o custo de transporte de matéria-prima se mantém o mesmo do cenário 2 . No entanto, o custo de transferência aumentou, de forma que o beneficiamento ocorra na UBS com melhores condições de fazer a entrega, em termos de transporte e ICMS. O custo total é maior que o dobro devido ao valor do ICMS. Se fosse retirado da solução do cenário 3 o custo de ICMS, o custo passaria a ser $\mathrm{R} \$ 587.508$, aproximadamente $\mathrm{R} \$ 40.000$ mais caro que o cenário 2. Dessa maneira, estes $\mathrm{R} \$ 40.000$ seriam a quantia gasta no chamado turismo fiscal. Entretanto, incorporando à solução do cenário 2 os custos de ICMS, seria obtido um custo total de $\mathrm{R} \$ 1.513 .269, \mathrm{R} \$ 280.441$ a mais. Com a vantagem da liminar judicial que garante a isenção de impostos para transferência entre unidades do mesmo grupo no cenário 4, o custo de ICMS é reduzido quase que pela metade, não evitando, no entanto, um aumento dos custos de transporte de matéria-prima e transferência. Nesta condição, uma unidade a mais de beneficiamento reduziria em $\mathrm{R} \$ 3,07$ por saco o custo considerado.

Considerando-se os custos diferenciados de preparo e beneficiamento do cenário 5 , o custo de transporte de matéria-prima foi aumentado e o de transferência reduziu-se, embora o custo com o ICMS tenha permanecido o mesmo em relação ao cenário 4. Para este caso, uma unidade de espigas a mais preparada na UBS MG proporcionaria uma redução de custos de R \$1,24 por saco. Já o cenário 6 ilustra o peso da isenção de ICMS para operações internas com insumos agropecuários, por meio da diferença dos custos de ICMS entre os cenários 6 e 3, que é de $\mathrm{R} \$ 848.880$. O custo do turismo fiscal calculado através da diferença dos custos de transporte entre o cenário 6 (i.e., R\$ $164.744+\mathrm{R} \$ 8.894+\mathrm{R} \$$ $444.153=\mathrm{R} \$ 617.791)$, e o cenário $2(\mathrm{R} \$ 163.862+\mathrm{R} \$ 0+$ $\mathrm{R} \$ 383.580=\mathrm{R} \$ 547.442$ ), é de R $\$ 70.349$, ou seja, superior ao do cenário 3 . Isso ocorre porque as condições do cenário 6 estimulam as transferências interestaduais e as UBSs estão localizadas nos Estados com maior demanda de sementes.

\section{CONSIDERAC̣ÕES FINAIS}

Este trabalho abordou o planejamento da produção e logística para empresas produtoras de sementes de milho. Um modelo de otimização linear foi desenvolvido e foram gerados seis cenários em um exemplo de rede baseado na rede da Empresa A, variando-se alguns parâmetros. Com base nestes experimentos, as expectativas para todos os cenários foram contempladas, evidenciando que as soluções do modelo científico correspondem ao modelo conceitual. Os tempos computacionais foram baixos, provendo flexibilidade na geração de vários cenários durante o planejamento. Além disso, verificou-se que a incorporação dos custos fiscais na função objetivo interfere consideravelmente nas variáveis de decisão, proporcionando redução de custos no planejamento da produção e logística, aumentando, conseqüentemente, a competitividade da empresa produtora de sementes.

Uma extensão deste trabalho é a aplicação do modelo apresentado para um período completo de safra e considerando toda a rede de uma empresa. Em um próximo artigo, pretende-se reportar os resultados de um estudo de caso com a aplicação do modelo aos dados completos de uma safra da Empresa A, como forma de validação do modelo, incluindo uma análise comparativa das soluções obtida pelo modelo e utilizada pela empresa.

Tabela 7: Comparação dos custos dos cenários estudados (em R\$).

\begin{tabular}{|c|c|c|c|c|c|c|c|}
\hline CEN. & $\begin{array}{c}\text { TRANSP. } \\
\text { MP }\end{array}$ & PREPARO & TRANSF. & BENGFIG. & $\begin{array}{c}\text { TRANSP. } \\
\text { PRODUTO } \\
\text { AGABADO }\end{array}$ & IGMS & TOTAL \\
\hline 1 & 234.139 & 0 & 11.954 & 0 & 377.164 & 0 & 623.257 \\
\hline 2 & 163.862 & 0 & 0 & 0 & 383.580 & 0 & 547.442 \\
\hline 3 & 163.862 & 0 & 39.821 & 0 & 383.825 & 665.320 & 1.252 .828 \\
\hline 4 & 187.235 & 0 & 85.458 & 0 & 353.599 & 291.105 & 917.397 \\
\hline 5 & 259.782 & 126.318 & 70.077 & 153.981 & 350.224 & 291.105 & 1.251 .487 \\
\hline 6 & 164.744 & 0 & 8.894 & 0 & 444.153 & 1.514 .200 & 2.131 .991 \\
\hline
\end{tabular}




\section{Artigo recebido em 21/06/2006 Aprovado para publicação em 10/11/2006}

\section{- Referências Bibliográficas}

ARENALES, M.; ARMENTANO, V. MORABITO, R.; YANASSE, H. Pesquisa Operacional. Editora Campus/Elsevier, Rio de Janeiro: 2006.

BROOKE, A.; KENDRICK, D.; MEERAUS, A. GAMS: a user's guide (release 2.25). The Scientific Press, San Francisco, CA, 1992.

CAIXETA-FILHO, J. V.; SWAAY-NETO, J. M. V.; WAGEMAKER, A. P.; Optimization of the Production Planning and Trade of Lily Flowers at Jan de Wit Company; Interfaces, v. 32, n. 1, p. 35-46, 2002.

CARNEIRO, J. W. P.; GUEDES, T. A., AMARAL, D. Descrição do tamanho de sementes de milho em lotes disponíveis no comércio. Revista Brasileira de Sementes, v. 23, n. 2, p. 209-214, 2001

COLIN, E. C.; CIPPARRONE, F. A. M.;SHIMIZU, T. "Otimização do custo de transporte na distribuição-armazenagem de açúcar. Produção, v. 9, n. 1, p. 23-30, 1999.

CONFAZ Convênios do ICMS. Disponível em: <http://www.fazenda.gov.br/confaz/>. Acesso em: 19 jun. 2006.
GOIÁS. Regulamento ICMS-GO. Disponível em: <http://www.sefaz. go.gov.br/>. Acesso em: 18 jun. 2006.

HAX, A.; CANDEA, D. Production and Inventory Management. New Jersey: Prentice-Hall, 1984.

JUNQUEIRA, R. A. R. Modelagem do planejamento agrícola, industrial e de transporte de uma empresa de produção de sementes de milho. Dissertação de Mestrado, Departamento de Engenharia de Produção, Universidade Federal de São Carlos, 2006.

KAWAMURA, M. S.; RONCONI, D. P., YOSHIZAKI, H. Optimizing transportation and storage of final products in the sugar and ethanol industry. Submetido para publicação no International Transactions in Operational Research, 2005.

KIUP, C. A. C. Algebraic languages for mathematical-programming. European Journal of Operational Research, v. 67, n. 1, p. 25-51, 1993.

MITROFF, I.; Betz, F.; Pondy, L. R. Sagasti, F. On Managing Science in the Systems Age: Two Schemas for the Study of Science as a whole Systems
Phenomenon. Interfaces, v. 4 , n. 3 , p. $46-58,1974$

MINAS GERAIS. Regulamento ICMS-MG. Disponível em: < http://www.fazenda. mg.gov.br/empresas/legislacao_tributaria/ricms/> . Acesso em: 18 jun. 2006.

MUNHOZ, J. R.; MORABITO, R. Um modelo baseado em programação linear e programação de metas para análise de um sistema de produção e distribuição de suco concentrado congelado de laranja. Gestão \& Produção, v. 8, n. 2, p. 139-159, 2001a.

MUNHOZ, J. R.; MORABITO, R. A goal programming model for frozen concentrated orange juice production and distribution system. OPSEARCH, v. 38, n. 6, p. $630-646,2001 \mathrm{~b}$.

NAHMIAS, S. Production and operations analysis. Irwin, Homewood, IL, 1995.

OLIVEIRA, J. A.; CARVALHO, M. L. M.; VIEIRA, M. G. G. C. V.; VON PINHO, E. V . R. Efeito do Método de Colheita na Qualidade Física, Fisiológica e Sanitária de Sementes de Milho, Revista Brasileira de Sementes, v. 19, n. 2, p. 200-206, 1997.
PAIVA, R. P. O.; MORABITO, R. Um modelo de otimização para o planejamento agregado da produção em usinas de açúcar e álcool. Aceito para publicação na Gestão \& Produção, 2006.

SÃO PAULO. Regulamento ICMS-SP Disponível em: <http://info.fazenda. sp.gov.br/>. Acesso em: 18 jun. 2006.

SIFRECA (Sistema de informação de fretes) Custo de momento de transporte de milho. Disponível em: < http://sifreca. esalq.usp.br/sifreca/pt/index.php $>$. Acesso em: 30 out. 2004.

TAUBE, M. Integrated planning for poultry production at Sadia, Interfaces, v. 26, p. 38-53, 1996.

YOSHIZAKI, H. Y. Y. Projeto de Redes de Distribuição Física Considerando a Influência do Imposto de Circulação de Mercadorias e Serviços. Tese de Livre-Docência, Escola Politécnica da Universidade de São Paulo, 2002.

YOSHIZAKI, H. T. Y.; MUSCAT, A. R. N. BIAZZI, J. L. Decentralizing ethanol distribution in southeastern Brazil. Interfaces, v. 26 , n. 6 , p. $24-34,1996$

\section{Agradecimento}

Os autores agradecem aos revisores anônimos pelos úteis comentários e sugestões. Este trabalho contou com o apoio da Logtrac Consultores Associados.

\section{- Sobre os autores}

Rogério de Ávila Ribeiro Junqueira

Logtrac Consultores Associados S/C.

End.: Rua Episcopal, 1675, ap. 101 - 13560-570 - São Carlos - SP

Tel.: (16) 3372-1539 Fax: (16) 3307-6424

E-mail: rogerio@logtrac.com.br

\section{Reinaldo Morabito}

Departamento de Engenharia de Produção

Universidade Federal de São Carlos

End.: Caixa Postal 676 - 13565-905 - São Carlos - SP

Tel.: (16) 3351-8237 r. 9216 Fax: (16) 3351-8240

E-mail: morabito@power.ufscar.br 